\title{
MICROSTRUCTURE AND PURITY OF NITIZr-BASED ALLOYS PREPARED BY A PLASMA METALLURGY PROCESS AND VACUUM INDUCTION MELTING
}

\author{
Václav STRUNG, Ivo SZURMAN, Tomáš ČEGAN, Daniel PETLÁK, Jiřina VONTOROVÁ \\ VŠB - Technical university of Ostrava, Faculty of Materials Science and Technology \\ 17. listopadu 15/2172, 70833 Ostrava - Poruba, Czech Republic, EU \\ vaclav.strung@vsb.cz
}

https://doi.org/10.37904/metal.2019.969

\begin{abstract}
$\mathrm{Ni}-45 \mathrm{Ti}-5 \mathrm{Zr}$ (at\%) alloy was prepared by two different methods - by plasma and vacuum induction melting. Two samples were cut out both the ingots - the first out the edge and the second out the centre of the ingots. The aim was to confirm homogeneity of the ingots. Metalographical sections were used for photodocumenting of a microstructure, for verifying of chemical composition with EDS analysis and for statistic description of phases. Moreover, both the ingots were used for determination of $C$ and $O$ contents. In the both cases, structure was polycrystaline with a significant $\mathrm{Zr}$ segregation along dendrite boundaries. Chemical composition for the centre and the edge of the ingots was different only for the ingot prepared by plasma metallurgy. Unfortunately, both the ingots were contaminated with higher $\mathrm{C}$ and $\mathrm{O}$ contents.
\end{abstract}

Keywords: NiTiZr-based alloys, microstructure, plasma metallurgy, vacuum induction melting, purity

\section{INTRODUCTION}

NiTi-based alloys are known as the most important shape memory alloys with a good memory effect and pseudoelasticity. These alloys use a phase transformation effect of austenite to martensite. Transformation temperature is about $100^{\circ} \mathrm{C}$. Higher transformation temperature can be obtain by alloying of NiTi with Au, Pd, $\mathrm{Pt}, \mathrm{Hf}$ and $\mathrm{Zr}$. Alloying with $\mathrm{Hf}$ and $\mathrm{Zr}$ is the most suitable due to their lower prices, although these alloys are still not used in practice. A disadvantage of the NiTiZr alloys is their low workability at room temperature. How a $\mathrm{Zr}$ content increases in these alloys, their hardness increases also but the workability and cold ductility significantly decrease. This can be improve with suitable preparation methods, such as plasma or vacuum induction melting [1-6].

The most important assumption for an application of the NiTiZr-based alloys is to manage their manufacturing process. It is incidental to high purity of raw materials. To avoid contamination with unwanted elements, a preparation of the NiTiZr-based alloys must be carried out in vacuum or protective atmosphere of argon (for example melting with plasma and vacuum induction furnaces). The most common contaminants are carbon and oxygen. Appropriate solidification conditions are the next important factor, because they are connected with micro- and macrosegregation. It is also important to prevent material contamination with non-metal inclusions, for example from electrodes or crucibles. $\mathrm{TiO}_{2}$ and $\mathrm{TiC}$ in $\mathrm{NiTi}$ cause changes in $\mathrm{Ni}$ and $\mathrm{Ti}$ concentrations and it leads to changes of transformation temperatures [6 - 8].

\section{EXPERIMENT}

Using plasma and vacuum induction melting, both ingots of Ni-45Ti- $5 \mathrm{Zr}$ (at\%) alloy were prepared. For plasma melting, the plasma furnace with a horizontal crystallizer was used. The device is situated at VSB - Technical university of Ostrava. A charge was repeatedly remelted with an $\mathrm{Ar}$ plasma column at the temperature of $4800^{\circ} \mathrm{C}$. The rate of crystallizer moving was $2 \mathrm{~cm} \cdot \mathrm{min}^{-1}$ (Figure 1). An advantage of the method is reaching 
of high working temperatures. A disadvantage is a possibility of melting contamination with oxygen when argon with low purity $(>4 \mathrm{~N} 6)$ is used.

The second ingot was prepared by charge melting in a vacuum induction furnace Linn Supercast -Titan under protective Ar atmosphere ( $6 \mathrm{~N}$ purity) at Regional Material Technology Research Centre. The charge was insert inside a corundum crucible with a graphite insert. The melting temperature was $1820{ }^{\circ} \mathrm{C}$. Melting was centrifugally cast into a graphite mould (Figure 2). An advantage of this method is reduction of $\mathrm{C}$ contamination if specially modified graphite insert with TiC surface layer is used. A disadvantage is impossibility of reaching of temperatures higher than $2.000^{\circ} \mathrm{C}$ or melting contamination with inclusions from inappropriately chosen crucible.

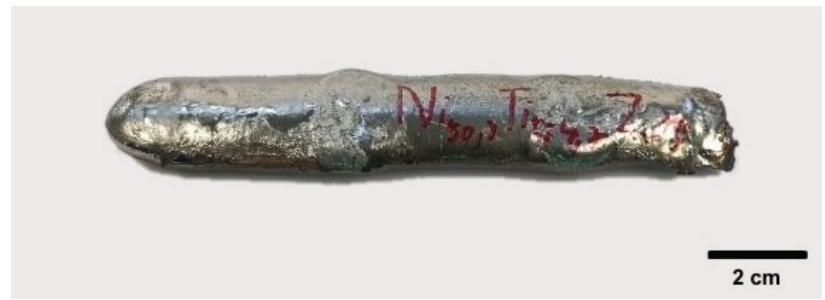

Figure 1 Ingot of Ni-45Ti-5Zr alloy prepared by plasma melting

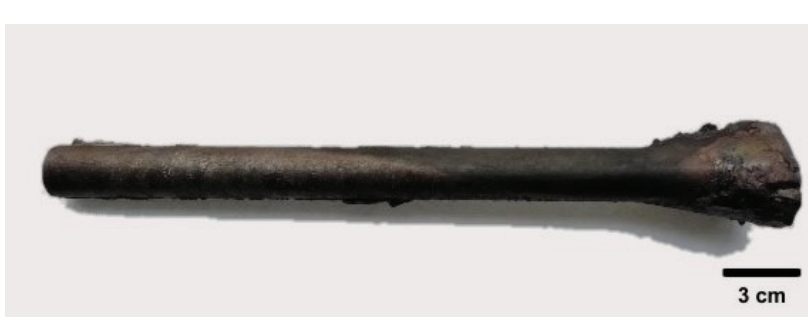

Figure 2 Ingot of Ni-45Ti-5Zr alloy prepared by vacuum induction melting

Two samples were cut out the centre and the edge of the ingots. The samples were used for photodocumenting of microstructure with optical microscope and for verification of chemical composition with EDS analysis. Moreover, an analysis of $\mathrm{C}$ and $\mathrm{O}$ contents was made.

\section{RESULTS}

Ground sections were etched with Kroll's etching solution ( $10 \mathrm{ml} \mathrm{HF}, 40 \mathrm{ml} \mathrm{NHO}$ and $50 \mathrm{ml} \mathrm{H}_{2} \mathrm{O}$ ). This solution etched only interdendritic space together with phases included. Figures $\mathbf{3}-\mathbf{7}$ show the microstructure of Ni$45 \mathrm{Ti}-5 \mathrm{Zr}$ alloy prepared by plasma melting shown in the centre (Figure 3 ) and the edge of the ingot (Figure 5) and by vacuum induction melting in the centre (Figure 4) and the edge of the ingot (Figure 6). Both ingots had polycrystalline structures with grains containing dendrites.

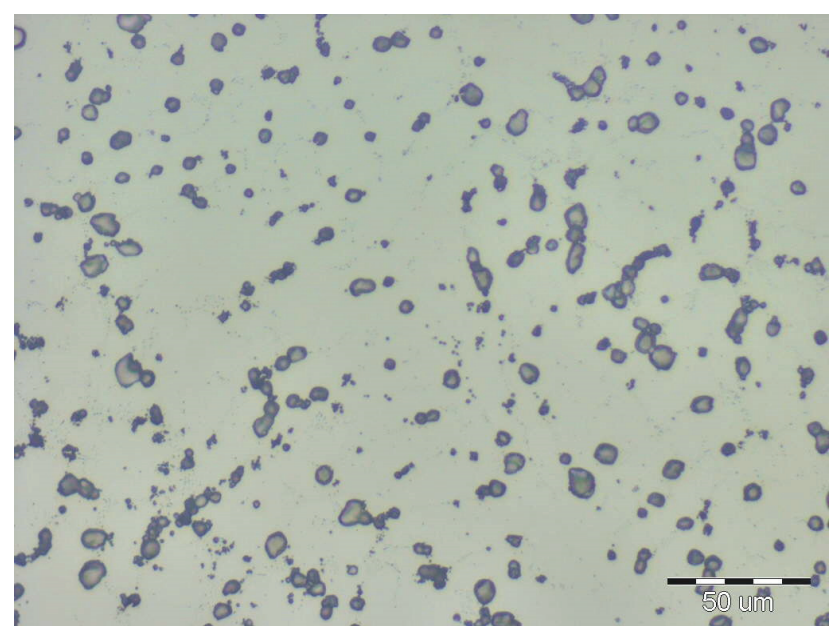

Figure $3 \mathrm{Ni}-45 \mathrm{Ti}-5 \mathrm{Zr}$ alloy prepared by plasma melting, centre of the ingot

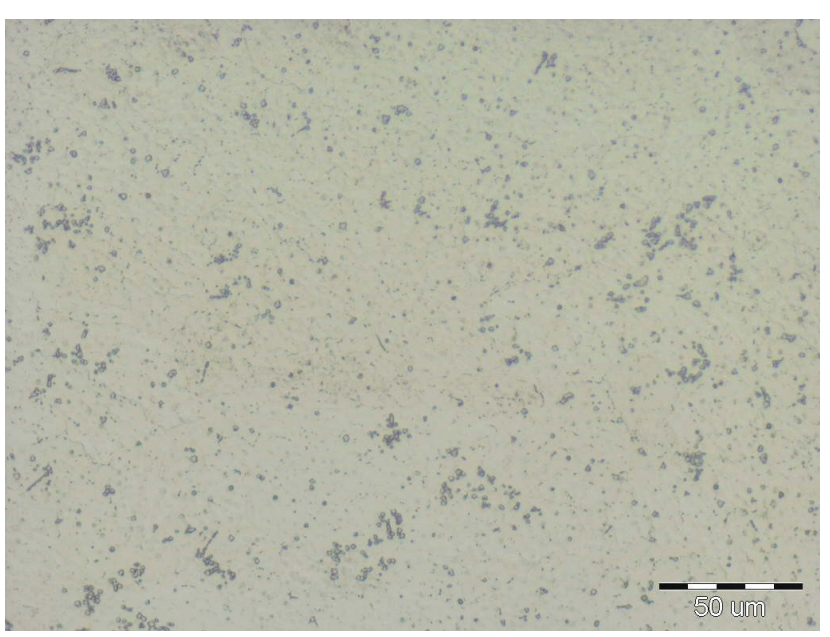

Figure $4 \mathrm{Ni}-45 \mathrm{Ti}-5 \mathrm{Zr}$ alloy prepared by vacuum induction melting, centre of the ingot 
Using a program for a quantitative image analysis ImageJ, statistical measurements of etched Zr phases were carried out. Measured quantities were a phase number ' $n$ ', a volume phase fraction ' $V$ and an average phase size ' $d$ ' (Table 1). In a case of the ingot prepared by plasma melting, its centre contains less $\mathrm{Zr}$ phases than the edge. It applies for the number and volume fraction, but the phases are almost doubly bigger. This diversity can be caused by irregular ingot shape in a direction of longitudinal axis. The ingot shape depends on the crystallizer shape (Figure 1). In a case of the second ingot, these are only small difference between the quantities. It can relate with a regular ingot shape along its longitudinal axis (Figure 2). This measurement has confirmed a homogeneous distribution and a size of $\mathrm{Zr}$ phases in the ingot prepared by vacuum induction melting.

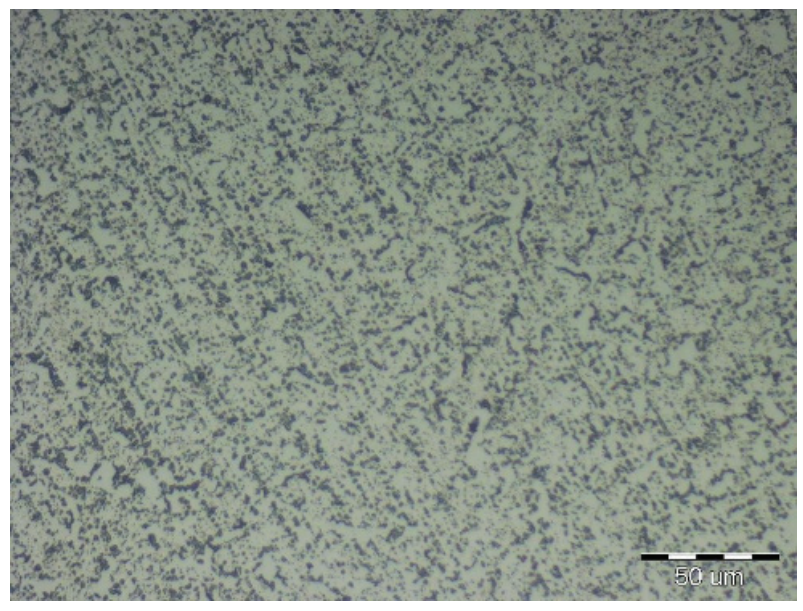

Figure $5 \mathrm{Ni}-45 \mathrm{Ti}-5 \mathrm{Zr}$ alloy prepared by plasma melting, edge of the ingot

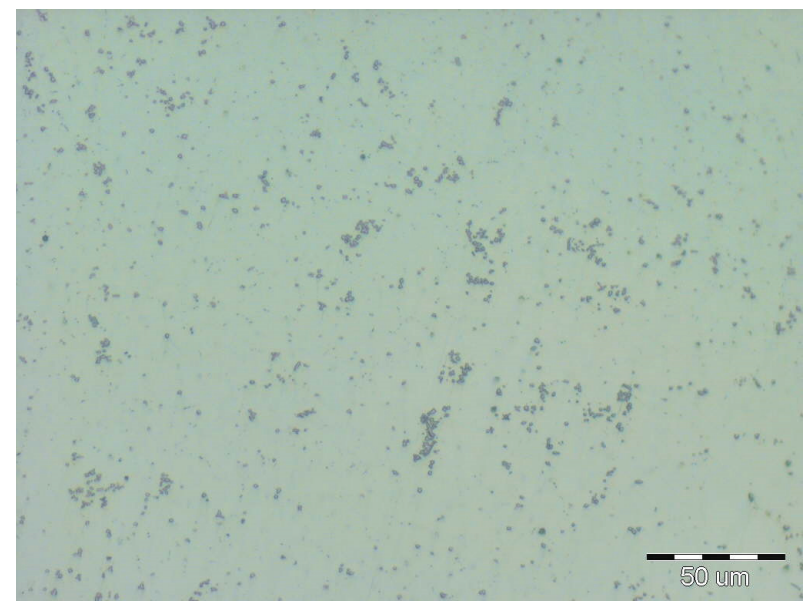

Figure $6 \mathrm{Ni}-45 \mathrm{Ti}-5 \mathrm{Zr}$ alloy prepared by vacuum induction melting, edge of the ingot

Table 1 Statistical description of $\mathrm{Zr}$ phases in the experimental ingots

\begin{tabular}{|c|c|c|c|c|}
\hline Preparation method & Place of Cutting & $\boldsymbol{n}(-)$ & $\boldsymbol{V}(\%)$ & $\boldsymbol{d}(\boldsymbol{\mu m})$ \\
\hline \multirow{2}{*}{ PM } & centre & 202 & 12.58 & 34.59 \\
\cline { 2 - 5 } & edge & 720 & 20.73 & 15.99 \\
\hline \multirow{2}{*}{ VIM } & centre & 165 & 3.39 & 11.42 \\
\cline { 2 - 5 } & edge & 124 & 2.36 & 10.57 \\
\hline
\end{tabular}

$\mathrm{PM}=$ plasma melting, $\mathrm{VIM}=$ vacuum induction melting

Nominal composition of the ingots was confirmed by results of area EDS analysis (Table 2). For this analysis, a scanning electron microscope Quanta FEG 450 equipped with a probe Apollo X was used. Chemical composition of the ingot prepared by plasma melting was heterogeneous in a direction of its longitudinal axis, it differed for each of three components. In a case of the ingot prepared by vacuum induction melting, the result was reverse. This ingot can be considered as chemically homogeneous in the direction of longitudinal axis.

Table 2 Results of area EDS analysis

\begin{tabular}{|c|c|c|c|c|}
\hline Preparation Method & Place of Cutting & $\boldsymbol{X}_{\mathrm{Ni}}(\mathrm{at} \%)$ & $\boldsymbol{X}_{\mathrm{Ti}}(\mathrm{at} \%)$ & $\boldsymbol{X}_{\mathbf{Z r}}(\mathrm{at} \%)$ \\
\hline \multirow{2}{*}{$\mathrm{PM}$} & centre & $53.51 \pm 0.16$ & $41.85 \pm 0.26$ & $4.64 \pm 0.13$ \\
\cline { 2 - 5 } & edge & $51.62 \pm 1.80$ & $45.71 \pm 1.61$ & $5.46 \pm 0.20$ \\
\hline \multirow{2}{*}{$\mathrm{VIM}$} & centre & $52.19 \pm 0.10$ & $42.86 \pm 0.12$ & $4.95 \pm 0.02$ \\
\cline { 2 - 5 } & edge & $52.53 \pm 0.09$ & $42.65 \pm 0.09$ & $4.82 \pm 0.05$ \\
\hline
\end{tabular}


The alloy should be in the range of NiTi monophase according to ternary diagram of Ni-Ti-Zr [9]. However high rate of crystallization of the alloy led to formation of dendritic structure accompanied by significant segregation of $Z r$ in the interdendritic space, which also contains lot of another phases. This applies for both method of preparation (Figures 7-10).

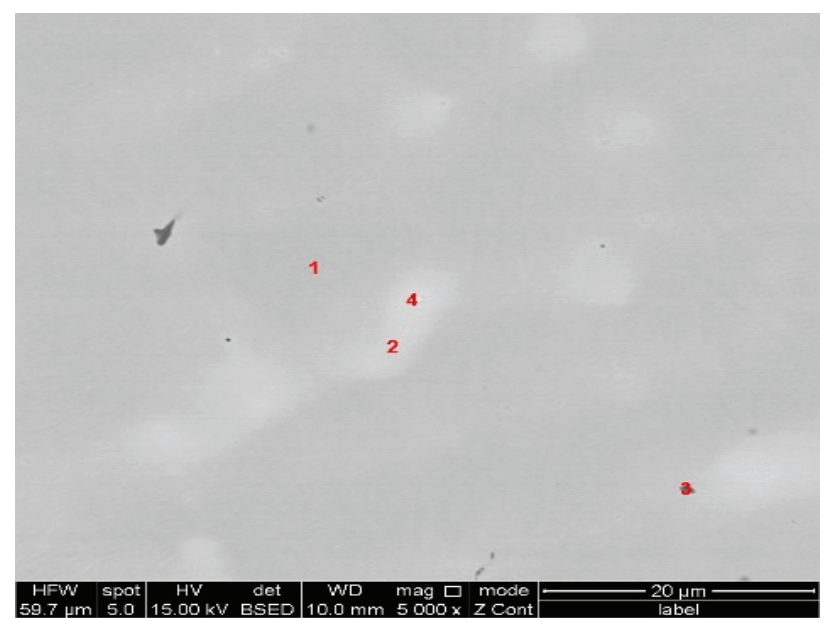

Figure 7 Ni-45Ti-5Zr, PM, centre: 1, 2 - (Ti, Zr)Ni, 3 - TiC, 4 - NiTiZr

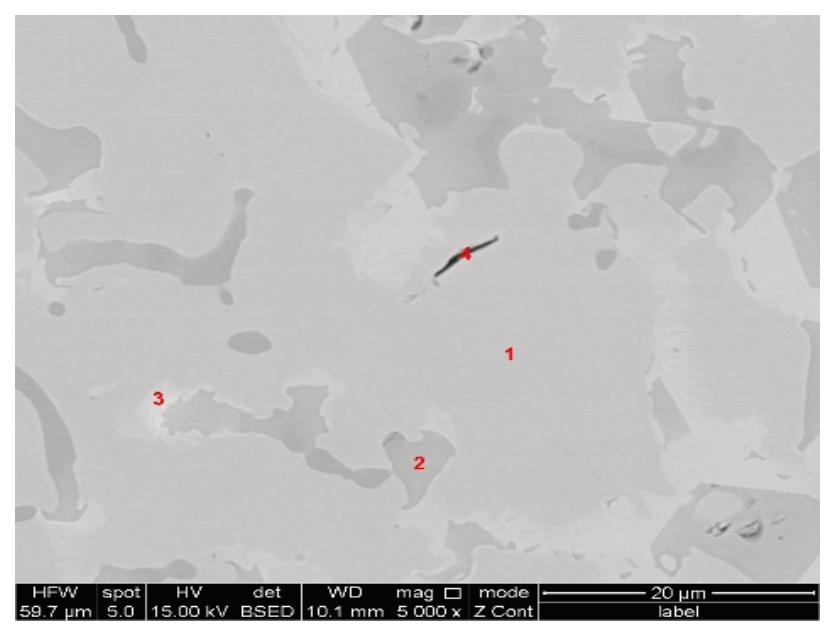

Figure 9 Ni-45Ti-5Zr, PM, edge: 1 - (Ti, Zr)Ni, 2 $\mathrm{Ti}_{2} \mathrm{Ni}, 3$ - NiTiZr, 4 - TiC

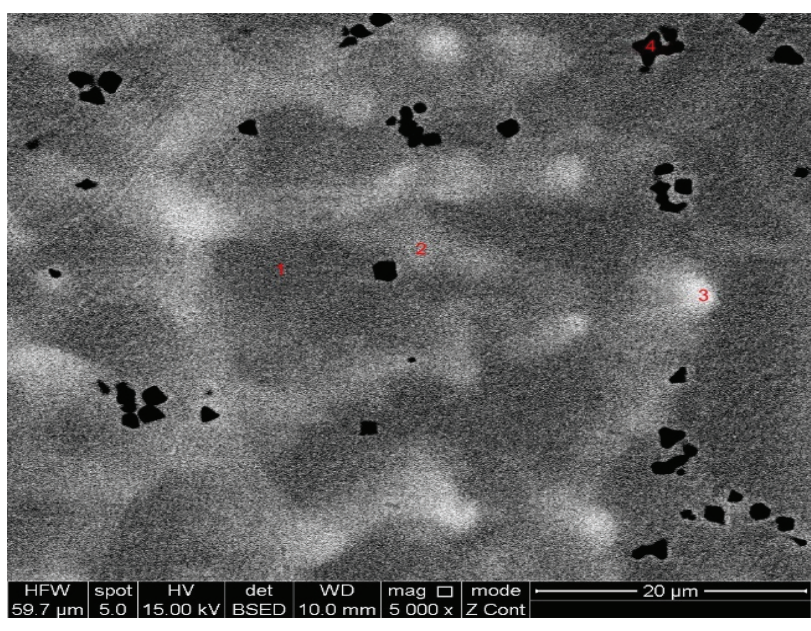

Figure $8 \mathrm{Ni}-45 \mathrm{Ti}-5 \mathrm{Zr}$, VIM, centre: 1, 2 - (Ti, Zr)Ni, 3 - NiTiZr, 4 - TiC

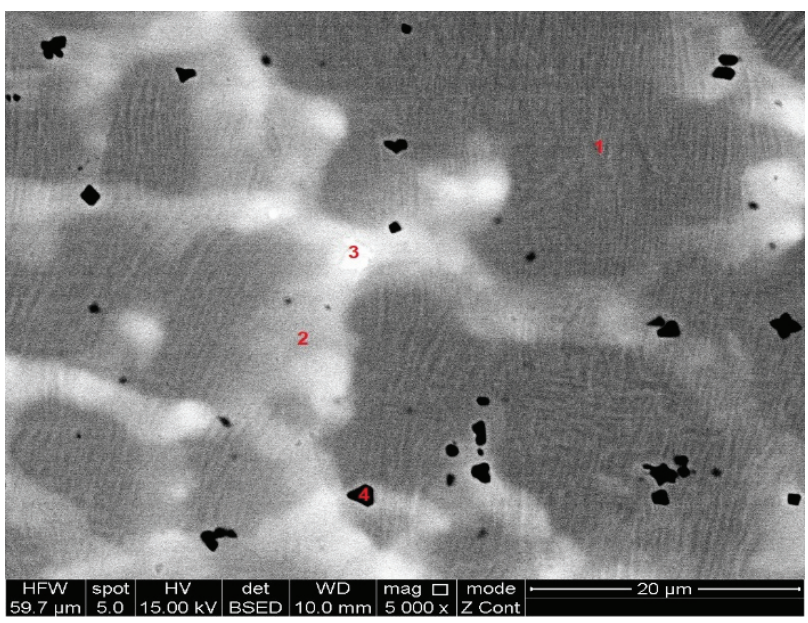

Figure $10 \mathrm{Ni}-45 \mathrm{Ti}-5 \mathrm{Zr}$, VIM, edge: 1, 2 - (Ti, Zr)Ni, 3 - NiTiZr, 4 - TiC

Results of point EDS analysis can be summarized as follows. Centers of dendrites match chemically to the nominal composition and form them NiTi monophase enriched by $\mathrm{Zr}$. Concetration of $\mathrm{Zr}$ increases in the direction from center of dendrites to the interdendritic space, in which the rich phases on this element may precipitate. In these cases, these could be precipitates of NiTiZr phase. The sample of the edge prepared by plasma melting contains probably $\mathrm{Ti}_{2} \mathrm{Ni}$ phase enriched by $\mathrm{Zr}$. Unfortunately, TiC precipitates was found in both ingots. Carbon - rich phases forms as result of technology of preparation in combination with higher melting temperatures. Table 3 assumes results of point EDS analysis for experimental Ni-45Ti-5Zr alloy.

Concentrations of oxygen and carbon were determined additionaly using devices Eltra ONH 2000 and Eltra CS 2000 at the RMTRC. Results are summarized in Table 4 and compared with norm ASTM 2063 - 05 [10]. which sets limit values $\mathrm{C}<0.05 \mathrm{wt} \%$ and $\mathrm{O}<0.05 \mathrm{wt} \%$ for forged NiTi wire for medical purposes. 
Table 3 Results of point EDS analysis

\begin{tabular}{|c|c|c|c|c|c|c|}
\hline $\begin{array}{c}\text { Preparation } \\
\text { method }\end{array}$ & $\begin{array}{l}\text { Place of } \\
\text { cutting }\end{array}$ & Point & $\boldsymbol{X}_{\mathrm{Ni}}(\mathrm{at} \%)$ & $\boldsymbol{X}_{\mathrm{Ti}}(\mathrm{at} \%)$ & Xzr $($ at $\%)$ & $x_{c}($ at $\%)$ \\
\hline \multirow{4}{*}{ PM } & \multirow{4}{*}{ centre } & point 1 & $53.53 \pm 0.10$ & $43.10 \pm 0.40$ & $3.37 \pm 0.30$ & \\
\hline & & point 2 & $55.47 \pm 0.11$ & $31.31 \pm 0.40$ & $13.23 \pm 0.29$ & \\
\hline & & point 3 & $5.35 \pm 0.85$ & $46.65 \pm 1.22$ & $3.12 \pm 0.09$ & 44.88 \\
\hline & & point 4 & $59.07 \pm 0.63$ & $21.87 \pm 2.64$ & $19.06 \pm 0.02$ & \\
\hline PM & edge & point 1 & $52.07 \pm 0.07$ & $43.45 \pm 0.04$ & $4.48 \pm 0.03$ & \\
\hline \multirow{3}{*}{ PM } & \multirow{3}{*}{ edge } & point 2 & $35.59 \pm 0.18$ & $58.65 \pm 0.60$ & $5.76 \pm 0.42$ & \\
\hline & & point 3 & $45.85 \pm 6.20$ & $41.00 \pm 4.93$ & $13.15 \pm 1.27$ & \\
\hline & & point 4 & $6.00 \pm 4.18$ & $46.57 \pm 2.93$ & $1.62 \pm 0.44$ & 45.8 \\
\hline \multirow{8}{*}{ VIM } & \multirow{4}{*}{ centre } & point 1 & $52.58 \pm 0.36$ & $44.51 \pm 0.41$ & $2.91 \pm 0.05$ & \\
\hline & & point 2 & $53.12 \pm 0.18$ & $39.49 \pm 1.35$ & $7.39 \pm 1.33$ & \\
\hline & & point 3 & $53.16 \pm 0.96$ & $32.58 \pm 1.55$ & $14.26 \pm 2.27$ & \\
\hline & & point 4 & $1.49 \pm 0.12$ & $38.97 \pm 0.30$ & $1.17 \pm 0.04$ & 58.3 \\
\hline & \multirow{4}{*}{ edge } & point 1 & $52.30 \pm 0.11$ & $45.07 \pm 0.15$ & $2.63 \pm 0.04$ & \\
\hline & & point 2 & $53.14 \pm 0.41$ & $39.94 \pm 0.33$ & $6.92 \pm 0.69$ & \\
\hline & & point 3 & $55.76 \pm 2.09$ & $29.84 \pm 5.64$ & $14.40 \pm 3.59$ & \\
\hline & & point 4 & $2.29 \pm 0.31$ & $52.76 \pm 1.01$ & $1.67 \pm 0.12$ & $43.28 \pm 0.82$ \\
\hline
\end{tabular}

Table 4 Results of analysis of $\mathrm{C}$ and $\mathrm{O}$ content in experimental ingots

\begin{tabular}{|c|c|c|c|}
\hline Preparation method & Place of cutting & wc (wt\%) & wo (wt\%) \\
\hline PM & centre & 0.0129 & 0.1150 \\
\hline VIM & centre & 0.1070 & 0.0740 \\
\hline
\end{tabular}

Both ingots, but mainly ingot prepared by plasma metling contain an above - limit of oxygen concentration despite using high purity argon (4N6 for PM and $6 \mathrm{~N}$ for VIM). The probable cause was use of piece of Ti. which according to supplier contain $0.13 \mathrm{wt} \% \mathrm{O}$. The limit concentration of carbon was broken only in the case of ingot prepared by VIM method. The cause was use of a crucible without protective layer of TIC, which prevents diffusion of $\mathrm{C}$ into the melt and application of high working temperature necessery to melt $\mathrm{Zr}$.

\section{CONCLUSION}

Two ingots of Ni-45Ti-5Zr (at\%) alloy were prepared by plasma and vacuum induction melting. It was demonstrated by an optical microscope, that both ingots consist many grains of different orientation. High speed of crystallization led to strong segregation of $\mathrm{Zr}$ in the direction from center of dendrites to the interdendritic space. EDS analysis demonstrated, that the nuclei of dendrites consisted of (Ti, Zr)Ni phase. In interdendritic space coexisted two types of other phases - first one was NiTiZr phase, second was unwanted $\mathrm{TiC}$ phase. The sample of the edge prepared by plasma melting contained also Ti2Ni phase. Analysis of contain of $C$ and $O$ confirmed above - limits values of these elements for both ingots. High concentration of $O$ was caused by use piece of $\mathrm{Ti}$, where the supplier guaranteed its high concentration. Carbon got into melt thanks to two factors - using a crucible without protecting diffusion layer of $\mathrm{TiC}$ and high working temperature necessary to melt Zr. 


\section{ACKNOWLEDGEMENT}

Supported by the Moravian-Silesian Region budget under the program „,Supporting Science and

Research in the Moravian-Silesian Region 2017" (RRC/10/2017). This work was created by the projects No. L01203 „Regional Material Technology Research Center-Sustainability Program“ funded by the Ministry of Education, Youth and Sports; No SP2019/128 „Preparation of optimalization of slot properties for automotive. electrotechnical and biomedical applications and their recycling"; No. SP2019/43 „Specific research in metallurgical, material and process engineering“.

\section{REFERENCES}

[1] KIM, S., PARK, CH. and HONG, J. Fracture toughness of TiNiHf alloys: A hybrid study using In-situ transmission electron microscopy. Experiments and finite element analyses. Materials Science \& Engineering A [online]. 2016. vol. 655, pp. 363-372 [viewed 2018-05-09]. Available from: DOI: 10.1016/j.msea.2016.01.016

[2] HSIEH, S. F., HSUE, W. S. and CHEN, S. L. Surface characteristics and shape recovery ability of Ti35.5Ni48.5Zr16 and Ni60Al24.5Fe15.5 ternary shape memory alloys. Journal of Alloys and Compounds [online]. 2013. vol. 571, no. 6, pp. 63-68 [viewed 2018-05-09]. Available from: DOI: 10.1016/j.jallcom.2013.03.111

[3] KIM, J.I., INAMURA, T, KIM, H.Y., HOSODA, H. and MIYAZAKI, S. Shape memory characteristics of Ti-22Nb-(28) $\mathrm{Zr}($ at\%) biomedical alloys. Materials Science and Engineering [online]. 2005. vol. 405, pp. 334 - 339 [viewed 2018-05-09]. Available from: DOI: 10.1016/j.msea.2005.05.050.

[4] KIM, H.Y., MIZUTANI, M. and MIYAZUKI, S. Crystallization process and shape memory properties of Ti-NiZr thin films. Acta Materialia [online]. 2009. vol. 57, pp. 1920-1930 [viewed 2018-05-09]. Available from: DOI: 10.1016/j.actamat.2008.12.036.

[5] KIM, H.Y., JINGUU, T., NAM, T. and MIYAZAKI, S. Cold workability and shape memory properties of novel Ti-Ni$\mathrm{Hf}-\mathrm{Nb}$ high-temperature shape memory alloys. Acta Materialia [online]. 2011. vol. 65, pp. 846-849 [viewed 201805-09]. Available from: DOI: 10.1016/j.scriptamat.2011.07.049.

[6] STRUNG, V., SZURMAN, I., POHLUDKA, M., PETLÁK, D., VONTOROVÁ, J. Microstructure and purity of the NiTiZr-based alloys prepared by a plasma metallurgy process. METAL 2018: $27^{\text {th }}$ International Conference on Metallurgy and Materials. Ostrava: TANGER, 2018, pp. 1734 - 1740

[7] KURSA, M., SZURMAN, I., DRÁPALA, J., LOSERTOVÁ, M. and GREGER, M. Shape memory materials on the base of Ni-Ti-Me and possibilities of controlling their transformation characteristics. 1st. ed. Ostrava: VŠB Technical University of Ostrava, 2005. 155 p. ISBN 80-248-0894-3. In Czech.

[8] HSIEH, S.F. and WU, S.K. Room-temperature phases observed in Ti53-xNi47Zrxhigh - temperature shape memory alloys. Journal of Alloys and Compounds [online]. 1998. vol. 266. pp. 276-282 [viewed 2018-05-09]. Available from: http://ntur.lib.ntu.edu.tw/bitstream/246246/86724/1/62.pdf.

[9] GUPTA, K.P. The Ni-Ti-Zr system (Nickel-Titanium-Zirconium). Journal of Phase Equilibria. 1999. vol. 20, no. 8, pp. 441-448.

[10] Designation F 2063 - 05: Standard specification for wrought nickel-titanium shape memory alloys for medical devices and surgical implants. United States of America, 2005, 1 - 4. 